\title{
Improvements of Nutrition Behavior Fitness and Body Fatness with a Short-Term after School Intervention Program
}

\author{
Katia Cristina Portero McLellan, Anna Lucia Vieira Bianchessi, Ana Elisa Rinaldi, Edilaine Michelin, \\ Roberto Carlos Burini \\ Center for Exercise Metabolism and Nutrition, Department of Public Health, School of Medicine, Sao Paulo State University (UNESP), \\ Botucatu, Brazil. \\ Email: kmclellan@fmb.unesp.br
}

Received July $4^{\text {th }}$, 2013; revised August $4^{\text {th }}, 2013$; accepted August $11^{\text {th }}, 2013$

Copyright (C 2013 Katia Cristina Portero McLellan et al. This is an open access article distributed under the Creative Commons Attribution License, which permits unrestricted use, distribution, and reproduction in any medium, provided the original work is properly cited.

\begin{abstract}
The prevalence of childhood obesity has been increasing worldwide and lifestyle changes are the most important strategies in managing this prevalence. This study aimed to describe the intervention effects of nutrition and physical activities offered as an after school short-term on outcomes of healthy nutrition practices, fitness and lowering fatness. This quasi-experimental study was conducted with a convenience sample of 59 caucasian children, aged $7.7 \pm 1.4$ years old (52.5\% girls) registered on a private school of a middle-size town located in Sao Paulo State, Brazil. The school-based 12-week intervention consisted of 2 weekly 60 minutes section, during 3 months, including a nutritional education and a physical activity curriculum. Anthropometric data was measured for all children at baseline and after 12 weeks. All parents were contacted and requested to complete questionnaire about child's eating behavior at baseline and after the 12-week program. After the intervention, children showed an increasing in the intake of fruits (64.3\%), vegetables (61.9\%), and water (52.0\%). Overall, 83.3\% of the children changed eating behavior according to the questionnaire responded by the parents. Waist circumference was significantly lower and abdominal strength improved after participating in the intervention program. Mean height and weight were significantly higher in boys and girls after a 12-week intervention. Although mean values of BMI remained the same after the intervention it was observed a decreasing in the prevalence of obesity among the children. Thus our study showed that a school-based intervention program focused on nutritional education and physical activity program promoted waist circumference reduction and decreased obesity without affecting the height growth along with improved fitness and healthy eating behavior. This intervention program would be feasible and replicable in others schools around the country.
\end{abstract}

Keywords: Obesity; Lifestyle; School-Based Intervention

\section{Introduction}

The prevalence of childhood obesity has been increasing in developed [1] and developing [2] countries. Data from the 2008-2009 Brazilian Household Survey indicated that approximately 33.5\% of children (ages 5 - 9 years) and $20.5 \%$ of adolescents (ages $10-19$ years) are above the weight considered healthy by the World Health Organization (WHO). Obesity prevalence increased from $2.3 \%$ to $14 \%$ (ages 5 to 9 years) and $0.5 \%$ to $5 \%$ (ages 10 to 19 years) between 1974-1975 and 2008-2009 [3,4]. Obese children are more likely to become obese adults $[5,6]$ and are at a higher risk of developing adverse health condi- tions such type 2 diabetes mellitus, the early-onset metabolic syndrome, subclinical inflammation, dyslipidemia, coronary artery diseases [2], and psychosocial outcomes [7]. The metabolic syndrome rates in Brazilian childhood are available from regional studies and range from $4 \%$ to $42.4 \%$ [8-12].

The increasing prevalence of obesity is due to complex interactions between genetic and environmental factors such as dietary intake and physical activity. The most important factors underling the obesity epidemic are high caloric intake coupled with limited energy expenditure [13]. Both obesity and excessive abdominal adiposity 
predispose children to be unfit in abdominal strength/ resistance and aerobic resistance. Excess of body adiposity increase the likelihood of poor trunk flexibility [14]. Moreover, low physical fitness is associated with higher sedentary behavior illustrated by the TV time [15].

Because of the increasing public health importance of childhood obesity, many intervention studies have been conducted in developed and developing countries. These studies performed interventions during school time [1620], or after school hours [21-26], aiming various target outcomes such as nutrition education [18,20], physical activity $[16,21-23]$ or a combination of these approaches [17,19,24-26].

A recent meta-analysis showed that school-based interventions that contain a physical activity component may be effective in helping to reduce BMI in children [27]. Therapeutic lifestyle changes and maintenance of regular physical activity are the most important strategies in managing childhood obesity $[2,28]$. The present study aimed to describe the intervention effects of nutrition and physical activities offered as an after school short-term outcomes of healthy nutrition practices, fitness and lowering fatness.

\section{Methods}

This quasi-experimental study was conducted with a convenience sample of 59 caucasian children (first to fifth grade students), aged $7.7 \pm 1.4$ years old ( $52.5 \%$ girls) from a private school of Sao Paulo State, Brazil. The study's aims and methods were presented to children's parents at the beginning of the academic year. Parents gave written consent for their children to participate in the study. Participating children were free of motor disorders that could impede participation in the physical activity education program. The study was approved by the Research Ethics Committee of School of Medicine of Sao Paulo State University-UNESP/Botucatu (protocol 579/2006).

The study was designed to be a school-based 12-week intervention, including a nutritional education and a physical activity program in which the children engaged in twice a week for 60 minutes. This program has been implemented in the school since 2005. It has been developed by the Nutritional and Exercise Metabolism Centre (CeMENutri) of the UNESP-Medical School which is a multi-professional teaching and research centre located in Botucatu city, a middle size city (in 2010, there were 127,328 inhabitants), in a middle western part of Sao Paulo, a Brazilian southeast state.

\subsection{Measurements}

Anthropometric measurements, including weight (kg), height $(\mathrm{cm})$, waist circumference (WC) were obtained according to standard protocols (WHO 1995). All the measurements were assessed the week before and immediately after the intervention program. Body Mass index was calculated for all the children. The diagnosis of overweight was based on the BMI equal to or higher than the 85th percentile and lower than the 95th percentile, and obesity was considered a BMI equal to or higher than the 95th percentile [28]. Waist circumference values and percentiles were classified according to McCarthy et al. (2001) [29].

Fitness tests including flexibility and abdominal strength/ resistance were measured according to standards protocols [30].

\subsection{Intervention}

The nutrition education and physical activity program were conducted both by certified professionals. The program consisted of two 60-minutes section per week, during 3 months. The intervention aimed to improve knowledge, attitudes and eating habits of the children along with increasing daily exercise. The program included lectures and information about human body, the importance of energy and nutrients, consequences of physical inactivity and high energy intake. It also included cooking classes, games and discussions about healthy/unhealthy food and drink, composition of food and drink, and the children's nutritional pyramid (Figure 1). The nutritionist had presented the nutrition and activity material in an engaging, interactive manner to encourage the children's participation. After each nutrition education session a healthy snack was provided for every child. Healthy cooking workshops were performed by a certified nutritionist where nutrition education focused on the increasing intake of fruits and vegetables and whole grain products, and the decreasing intake of foods rich in fat, salt and sugar. A healthy meals/recipes book was developed to achieve children's needs and provided to the parents. The physical activity program combined games for outdoors and activity games, looking for coordination and flexibility improvements.

\subsection{Qualitative Questionnaire}

All parents were contacted and requested to complete questionnaire after the 12-week intervention program. Parents were queried about the project content and changes in children's eating behavior (Figure 2).

\subsection{Statistical Analysis}

The analyses were performed by using SAS, version 9.1. The data were described as mean \pm SD. Sample normality was tested by means of the Shapiro-Wilk test. Difference between baseline and after 12-week intervention of 


\begin{tabular}{|c|c|c|}
\hline Activity & Description & Objective \\
\hline "Food pyramid" & $\begin{array}{l}\text { Several food packages that are part of the Food pyramid are hidden. A picture of } \\
\text { the Brazilian Food pyramid explaining food distribution is given to each child. } \\
\text { Children are divided in groups and each group must find the hidden foods and } \\
\text { build its own pyramid, considering the recommended servings. }\end{array}$ & $\begin{array}{l}\text { To explain the distribution of } \\
\text { Brazilian food pyramid, the } \\
\text { food groups, their portions } \\
\text { and serving size. }\end{array}$ \\
\hline "Hunting the grains" & $\begin{array}{l}\text { The children are divided into teams. Each team receives a container with } \\
\text { different kinds of vegetables and other grains. Each group should separate } \\
\text { each vegetable and put it in the specific container. The group that separates } \\
\text { the vegetables correctly and faster wins. It should also be shown the } \\
\text { recommended intake in household measure. }\end{array}$ & $\begin{array}{l}\text { To recognize the different types of } \\
\text { vegetables and the importance of its } \\
\text { daily consumption. Samples will be } \\
\text { available for tasting. }\end{array}$ \\
\hline “Striking Fat” & $\begin{array}{l}\text { In bowling pins it was stuck pictures of foods rich in saturated and trans fatty } \\
\text { acids, and foods with polyunsaturated and monounsaturated fatty acids. The } \\
\text { children are divided into groups and each group must strike the biggest number } \\
\text { of pins with foods rich in saturated and trans fatty acids. }\end{array}$ & $\begin{array}{l}\text { To teach about foods rich in fat } \\
\text { and the difference between types } \\
\text { of fat. }\end{array}$ \\
\hline "Sensory: touch" & $\begin{array}{l}\text { Different types of fruits, vegetables and tubers are placed into boxes with a } \\
\text { small hole. The activity is performed individually and each child receives a } \\
\text { sheet with the number of each box and must fill in the name of the food that } \\
\text { is inside the corresponding box. At the end of the activity the coordinator } \\
\text { presents the foods to the children. }\end{array}$ & $\begin{array}{l}\text { To stimulate the sensorial ability of } \\
\text { touching and to introduce foods that } \\
\text { might be unknown for many children. } \\
\text { Some of the food will be available } \\
\text { for tasting. }\end{array}$ \\
\hline "Full Cup" & $\begin{array}{l}\text { Children are divided into teams where each member, in turns, uses sponge } \\
\text { to absorb as much water as possible from the bucket, at then squeeze it into } \\
\text { cups, mugs or bottles. The amount of water in cups, mugs or bottles should } \\
\text { match the recommended daily intake of water. The winner team is the one } \\
\text { that finishes the race and hit the recommendation. }\end{array}$ & $\begin{array}{l}\text { To teach about the importance of } \\
\text { water intake and its recommended } \\
\text { daily intake }\end{array}$ \\
\hline "Right Plate" & $\begin{array}{l}\text { A plastic plate is given to each child. Pictures of different foods are available } \\
\text { and they have to pick healthy choices of food for different meals (breakfast, } \\
\text { lunch, snack and dinner). }\end{array}$ & $\begin{array}{l}\text { To discuss about variety, quality } \\
\text { and harmony of food for different } \\
\text { meals (healthy choices). }\end{array}$ \\
\hline “Grocery time” & $\begin{array}{l}\text { Children are divided into groups. It is provided several containers with } \\
\text { replicas of food and each group simulates a purchase at the grocery } \\
\text { store. It is subsequently held a discussion on the items chosen. }\end{array}$ & $\begin{array}{l}\text { To discuss the quality of the } \\
\text { purchase in relation to the } \\
\text { nutrients of each food item on it. }\end{array}$ \\
\hline "Memory game" & $\begin{array}{l}\text { This game is about the right amount of food that should be consumed daily } \\
\text { in each of the food pyramid groups. Each pair in the game is matched by a } \\
\text { picture of the food and its respective recommended serving size. }\end{array}$ & $\begin{array}{l}\text { To show the food groups and } \\
\text { the recommended daily intake } \\
\text { of each one. }\end{array}$ \\
\hline "Food quiz" & $\begin{array}{l}\text { The children are divided into groups and they are asked questions about } \\
\text { healthy eating. To answer the questions a member of each group should } \\
\text { run and ring the bell. If the group that rings the bell cannot answer the } \\
\text { question, the turn goes to the other group and if this group does not know } \\
\text { the answer, it goes back to the first group. Wins the group that answers } \\
\text { correctly most of the questions. }\end{array}$ & $\begin{array}{l}\text { To check the level of children's l } \\
\text { earning on the nutrition topics } \\
\text { discussed } \\
\text { previously. }\end{array}$ \\
\hline
\end{tabular}

Figure 1. Activities performed during the program.

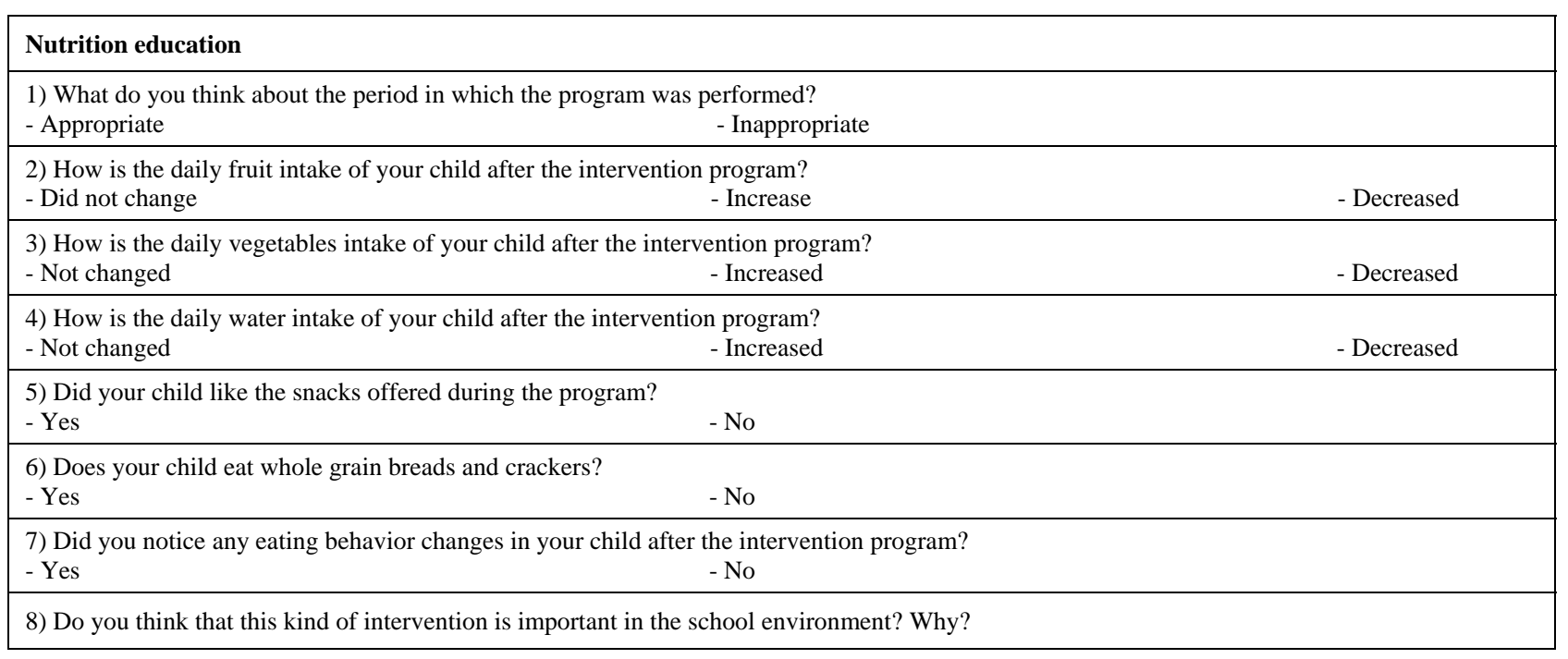

Figure 2. Questionnaire sent to parents after the intervention program. 
variables was analyzed by paired student's t test after. The effect between categories of BMI, WC, flexibility, strength/abdominal resistance and aerobic resistance was analyzed by means of chi-square test. The results were discussed based on the level of significance of $p<0.05$.

\section{Results}

The characteristics of the study population at baseline and after the intervention are shown in Table 1. Mean height was significantly higher by $2.0 \mathrm{~cm}$ among boys and $1.0 \mathrm{~cm}$ among girls after a 12-week intervention. Body weight was also higher by $0.54 \mathrm{~kg}$ among boys and $0.57 \mathrm{~kg}$ among girls. Although mean values of BMI remained the same after the intervention it was noticed a decrease in the prevalence of obesity of among the children. Waist circumference was significantly lower and abdominal strength improved after participating in the intervention program. It was also noticed that flexibility improved among girls and aerobic resistance decreased among boys after 12 weeks of intervention.

There were no statistically significant differences in the nutritional status and fitness of children after the intervention. However, the prevalence of obesity decreased in $3.4 \%$, abnormal waist circumference decreased in $6.8 \%$, and abnormal strength/abdominal resistance decreased in $17 \%$ (Table 2).

Analysis of children's food behavior after the intervention program showed an increase in the intake of fruits (64.3\%), vegetables (61.9\%), and water $(52.0 \%)$. Overall, $83.3 \%$ of the children changed eating behavior according to the questionnaire responded by the parents (Table 3).

Table 1. Characteristics of the study population at baseline and after a 12-week intervention.

\begin{tabular}{|c|c|c|c|c|c|c|c|c|}
\hline & \multicolumn{4}{|c|}{ Male } & \multicolumn{4}{|c|}{ Female } \\
\hline & $\mathrm{n}$ & Baseline & 12-week & $\mathrm{p}$ & $\mathrm{n}$ & Baseline & 12-week & $\mathrm{p}$ \\
\hline Age (years) & 28 & $7.57 \pm 1.50$ & $7.78 \pm 1.34$ & $<0.05$ & 31 & $7.81 \pm 1.35$ & $8.00 \pm 1.53$ & $<0.05$ \\
\hline Body weight (kg) & 28 & $35.90 \pm 10.68$ & $36.44 \pm 10.59$ & $<0.05$ & 31 & $32.67 \pm 8.83$ & $33.24 \pm 8.96$ & 0.001 \\
\hline Height (m) & 28 & $1.31 \pm 0.10$ & $1.33 \pm 0.10$ & $<0.001$ & 31 & $1.31 \pm 0,10$ & $1.32 \pm 0.10$ & $<0.001$ \\
\hline Body Mass Index $\left(\mathrm{kg} / \mathrm{m}^{2}\right)$ & 28 & $20.47 \pm 4.42$ & $20.41 \pm 4.33$ & 0.503 & 31 & $18.61 \pm 3.25$ & $18.61 \pm 3.24$ & 0.971 \\
\hline Waist Circumference (cm) & 28 & $67.96 \pm 11.80$ & $66.46 \pm 11.08$ & 0.001 & 31 & $62.53 \pm 9.76$ & $61.32 \pm 8.93$ & 0.001 \\
\hline Flexibility (cm) & 18 & $23.89 \pm 4.60$ & $23.44 \pm 6.74$ & 0.685 & 23 & $25.65 \pm 6.83$ & $26.74 \pm 6.71$ & $<0.05$ \\
\hline Strength/abdominal resistance (rep/min) & 18 & $19.72 \pm 12.48$ & $24.00 \pm 11.60$ & $<0.001$ & 23 & $19.35 \pm 6.38$ & $22.13 \pm 8.60$ & $<0.05$ \\
\hline Aerobic resistance (m) & 18 & $1023.33 \pm 263.37$ & $841.67 \pm 263.38$ & $<0.001$ & 23 & $897.56 \pm 208.76$ & $898.91 \pm 163.53$ & 0.966 \\
\hline
\end{tabular}

$\mathrm{rep} / \mathrm{min}=$ replications per minute.

Table 2. Nutritional status and fitness of the study population at baseline and after a 12-week intervention.

\begin{tabular}{|c|c|c|c|c|c|}
\hline & $\mathrm{n}$ & Baseline (\%) & $\mathrm{n}$ & 12-week (\%) & $\mathrm{p}$ \\
\hline \multicolumn{6}{|l|}{ Body Mass Index } \\
\hline Normal weight & 23 & 39.0 & 22 & 37.3 & 0.7042 \\
\hline Overweight & 13 & 22.0 & 16 & 27.1 & \\
\hline Obesity & 23 & 39.0 & 21 & 35.6 & \\
\hline \multicolumn{6}{|c|}{ Waist Circumference } \\
\hline Normal & 24 & 40.7 & 28 & 47.5 & 0.6811 \\
\hline Abnormal & 35 & 59.3 & 30 & 52.5 & \\
\hline \multicolumn{6}{|l|}{ Flexibility } \\
\hline Normal & 28 & 68.3 & 28 & 68.3 & 1.0000 \\
\hline Abnormal & 13 & 31.7 & 13 & 31.7 & \\
\hline \multicolumn{6}{|c|}{ Strength/abdominal resistance } \\
\hline Normal & 20 & 48.8 & 27 & 65.8 & 0.1182 \\
\hline Abnormal & 21 & 51.2 & 14 & 34.2 & \\
\hline \multicolumn{6}{|l|}{ Aerobic resistance } \\
\hline Normal & 13 & 31.7 & 8 & 19.5 & 0.2059 \\
\hline Abnormal & 28 & 68.3 & 33 & 80.5 & \\
\hline
\end{tabular}


Table 3. Qualitative questionnaire about child's eating behavior after the intervention program.

\begin{tabular}{|c|c|}
\hline & $\%$ \\
\hline \multicolumn{2}{|c|}{ Period of the program } \\
\hline Appropriate & 92.8 \\
\hline Inappropriate & 7.1 \\
\hline \multicolumn{2}{|l|}{ Fruit intake } \\
\hline Did not change & 30.9 \\
\hline Increased & 64.3 \\
\hline Decreased & 4.8 \\
\hline \multicolumn{2}{|l|}{ Vegetables intake } \\
\hline Did not change & 38.1 \\
\hline Increased & 61.9 \\
\hline Decreased & - \\
\hline \multicolumn{2}{|l|}{ Water intake } \\
\hline Did not change & 47.7 \\
\hline Increased & 52.3 \\
\hline Decreased & - \\
\hline \multicolumn{2}{|c|}{ Child liked the snacks offered } \\
\hline Yes & 100.0 \\
\hline No & - \\
\hline \multicolumn{2}{|c|}{ Child eat whole grain } \\
\hline Yes & 34.1 \\
\hline No & 65.9 \\
\hline \multicolumn{2}{|c|}{ Child has changed eating behavior } \\
\hline Yes & 83.3 \\
\hline No & 16.7 \\
\hline
\end{tabular}

\section{Discussion}

The purpose of our study was to document the results of a short-term school-based intervention program on lifestyle (nutrition and physical activity) of Brazilian children. The improvement of fitness and eating behavior led to a decrease in the prevalence of obesity, suggesting that it may be possible to control/reduce this problem in schools. The program not only decreased the prevalence of obesity but also improve children's fitness by increasing abdominal strength and physical resistance. Moreover, our intervention program improved children dietary quality by increasing the intake of fruits, vegetables and water. We believe that the parental involvement in this program played an important role in child's eating behavior changes as they were informed of the purpose of the study and were informed about their child's nutrition status over time. Besides, parental involvement increases participation of children in the program and help children makes the right choices and planning a balanced meal. The implementation of this short-term after-school intervention was successful and well accepted by parents and children.

Many intervention programs promoting physical activity and healthy diet have been demonstrated to be effective in several countries [24,26,31-33]. Most interventions showed improvement in health knowledge and health-related behaviors, including consumption of lowfat diet, increase in fruits and vegetables intake, and more physical activity [31,34]. Our short term intervention program (12 weeks) was successful in reducing body fatness and improving fitness and eating behavior of school children. Some of studies we reviewed had a length of intervention ranging from four weeks to three years [21,23,26,32], yet evidences suggest that a short intervention period might be associated with better outcomes $[21,23,35]$.

The prevalence of overweight and obesity in our study were higher in boys than in girls. After the intervention the prevalence of obesity decreased $3.8 \%$ in boys and $3.0 \%$ in girls. Small shifts in BMI may be more effective at a population level than simply reducing the prevalence of obesity [36].

Inadequate eating behavior and sedentary lifestyle predispose to childhood obesity. There are interactions of many factors that contribute to the obesogenic environments and affect children's weight, such as individual factors, home influences, and school factors. Afterschool intervention programs that promote an open-air physical activity along with healthy cooking class replaces a time that would be probably spent by children in front of the television or playing with computer and video games.

This study had several potential limitations: the children's group was not separately to meet their age-appropriated developmental and gender issue; the intervenetion were applied to a small number of children and thus may not be representative; lack of control group.

Despite of these limitations, out data shows successfully the efficacy of a multidisciplinary school intervenetion to reduce body fat and improve fitness and healthy eating behavior in children. The increased prevalence of childhood obesity is an indicator of public health problem. High-risk screening and effective health educational should be priority especially in developing countries.

\section{Conclusion}

Our study showed that a school-based intervention program focused on nutritional education and physical ac- 
tivity program promote waist circumference reduction, improve fitness and healthy eating behavior. This intervention program would be feasible and replicable in others schools around the country.

\section{Acknowledgements}

Pró Reitoria de Pesquisa da UNESP and FUNDUNESP, for providing funds for the publication fee.

\section{REFERENCES}

[1] C. L. Ogden, M. D. Carroll, L. R. Curtin, et al., "Prevalence of High Body Mass Index in US Children and Adolescents, 2007-2008," The Journal of the American Medical Association, Vol. 303, No. 3, 2010, pp. 242-249. http://dx.doi.org/10.1001/jama.2009.2012

[2] N. Gupta, K. Goel, P. Shah, et al., "Childhood Obesity in Developing Countries: Epidemiology, Determinants, and Prevention,” Endocrine Reviews, Vol. 33, No. 1, 2012, pp. 48-70. http://dx.doi.org/10.1210/er.2010-0028

[3] IBGE, "Fundação Instituto Brasileiro de Geografia e Estatística. Estudo Nacional das Despesas Familiares; Dados Preliminares. Consumo; Antropometria,” IBGE, Região V. Rio de Janeiro, 1977.

[4] IBGE, "Fundação Instituto Brasileiro de Geografia e Estatística. Pesquisas de Orçamentos Familiares 2008-2009. Antropometria e Estado Nutricional de Crianças, Adolescentes e Adultos no Brasil,” Rio de Janeiro, 2010.

[5] M. K. Serdula, D. Ivery, R. J. Coates, et al., "Do Obese Children Become Obese Adults? A Review of the Literature,” Preventive Medicine, Vol. 22, No. 2, 1993, pp. 167177. http://dx.doi.org/10.1006/pmed.1993.1014

[6] R. C. Whitaker, J. A. Wright, M. S. Pepe, et al., "Predicting Obesity in Young Adulthood from Childhood and Parental Obesity," The New England Journal of Medicine, Vol. 337, No. 13, 1997, pp. 869-873. http://dx.doi.org/10.1056/NEJM199709253371301

[7] D. S. Freedman, Z. Mei, S. R. Srinivasan, et al., "Cardiovascular Risk Factors and Excess Adiposity among Overweight Children and Adolescents: The Bogalusa Heart Study," The Journal of Pediatrics, Vol. 150, No. 1, 2007, pp. 12-17.e2.

[8] A. E. Rinaldi, G. D. Pimentel, A. F. Pereira, et al., "Metabolic Syndrome in Overweight Children from the City of Botucatu—Sao Paulo State-Brazil: Agreement among Six Diagnostic Criteria,” Diabetology \& Metabolic Syndrome, Vol. 2, No. 1, 2010, p. 39. http://dx.doi.org/10.1186/1758-5996-2-39

[9] A. P. Ferreira, C. E. Oliveira and N. M. Franca, "Metabolic Syndrome and Risk Factors for Cardiovascular Disease in Obese Children: The Relationship with Insulin Resistance (HOMA-IR)," Journal de Pediatria, Vol. 83, No. 1, 2007, pp. 21-26. http://dx.doi.org/10.2223/JPED.1562

[10] R. C. da Silva, W. L. Miranda, A. R. Chacra, et al., "Metabolic Syndrome and Insulin Resistance in Normal Glucose Tolerant Brazilian Adolescents with Family His- tory of Type 2 Diabetes,” Diabetes Care, Vol. 28, No. 3, 2005, pp. 716-718.

http://dx.doi.org/10.2337/diacare.28.3.716

[11] C. G. Buff, E. Ramos, F. I. S. Souza, et al., "Frequency of Metabolic Syndrome in Overweight and Obese Children and Adolescents,” The Revista Paulista de Pediatria, Vol. 25, No. 3, 2007, pp. 221-226. http://dx.doi.org/10.1590/S0103-05822007000300005

[12] M. S. F. Souza, R. B. Leme, R. R. Franco, et al., "Metabolic Syndrome and Obese and Overweight Adolescents," The Revista Paulista de Pediatria, Vol. 25, No. 3, 2007, pp. 214-220. http://dx.doi.org/10.1590/S0103-05822007000300004

[13] F. M. Biro and M. Wien, "Childhood Obesity and Adult Morbidities," The American Journal of Clinical Nutrition, Vol. 91, No. 5, 2010, pp. 1499S-1505S. http://dx.doi.org/10.3945/ajcn.2010.28701B

[14] V. Andreasi, E. Michelin, A. E. Rinaldi, et al., "Physical Fitness and Associations with Anthropometric Measurements in 7 to 15-Year-Old School Children,” Journal de Pediatria, Vol. 86, No. 6, 2010, pp. 497-502.

[15] J. C. Angelo, “Associação da Aptidão Física com Indicadores Socioeconômicos, Tempo de TV e Prática de Atividades Físicas de Escolares com Excesso de Peso,” Monografia de Conclusão de Curso de Aperfeiçoamento/ Especialização em Exercício Físico Nutrição e Medicina na Saúde e no Esporte, Universidade Estadual Paulista Júlio de Mesquita Filho, 2009.

[16] J. E. Donnelly, J. L. Greene, C. A. Gibson, et al., "Physical Activity across the Curriculum (PAAC): A Randomized Controlled Trial to Promote Physical Activity and Diminish Overweight and Obesity in Elementary School Children," Preventive Medicine, Vol. 49, No. 4, 2009, pp. 336-341. http://dx.doi.org/10.1016/j.ypmed.2009.07.022

[17] B. Caballero, T. Clay, S. M. Davis, et al., "Pathways: A School-Based, Randomized Controlled Trial for the Prevention of Obesity in American Indian Schoolchildren," The American Journal of Clinical Nutrition, Vol. 78, No. 5, 2003, pp. 1030-1038.

[18] R. Sichieri, A. Paula Trotte, R. A. de Souza, et al., "School Randomised Trial on Prevention of Excessive Weight Gain by Discouraging Students from Drinking Sodas," Public Health Nutrition, Vol. 12, No. 2, 2009, pp. 197-202. http://dx.doi.org/10.1017/S1368980008002644

[19] P. D. Angelopoulos, H. J. Milionis, E. Grammatikaki, et al., "Changes in BMI and Blood Pressure after a School Based Intervention: The CHILDREN Study,” European Journal of Public Health, Vol. 19, No. 3, 2009, pp. 319325. http://dx.doi.org/10.1093/eurpub/ckp004

[20] G. D. Foster, S. Sherman, K. E. Borradaile, et al., “A Policy-Based School Intervention to Prevent Overweight and Obesity,” Pediatrics, Vol. 121, No. 4, 2008, pp. e794e802. http://dx.doi.org/10.1542/peds.2007-1365

[21] O. Matvienko and I. Ahrabi-Fard, "The Effects of a 4Week After-School Program on Motor Skills and Fitness of Kindergarten and First-Grade Students," American Journal of Health Promotion, Vol. 24, No. 5, 2010, pp. 299303. http://dx.doi.org/10.4278/ajhp.08050146

[22] Z. Yin, B. Gutin, M. H. Johnson, et al., “An Environmen- 
tal Approach to Obesity Prevention in Children: Medical College of Georgia FitKid Project Year 1 Results,” Obesity Research, Vol. 13, No. 12, 2005, pp. 2153-2161. http://dx.doi.org/10.1038/oby.2005.267

[23] M. J. Duncan, Y. Al-Nakeeb and A. M. Nevill, "Effects of a 6-Week Circuit Training Intervention on Body Esteem and Body Mass Index in British Primary School Children,” Body Image, Vol. 6, No. 3, 2009, pp. 216-220. http://dx.doi.org/10.1016/j.bodyim.2009.04.003

[24] C. Graf, B. Koch, B. Bjarnason-Wehrens, et al., "Who Benefits from Intervention in, as Opposed to Screening of, Overweight and Obese Children?” Cardiology in the Young, Vol. 16, No. 5, 2006, pp. 474-480. http://dx.doi.org/10.1017/S1047951106000667

[25] B. M. Melnyk, L. Small, D. Morrison-Beedy, et al., "The COPE Healthy Lifestyles TEEN Program: Feasibility, Preliminary Efficacy, \& Lessons Learned from an after School Group Intervention with Overweight Adolescents,” Journal of Pediatric Health Care, Vol. 21, No. 5, 2007, pp. 315-322. http://dx.doi.org/10.1016/j.pedhc.2007.02.009

[26] R. Vandongen, D. A. Jenner, C. Thompson, et al., “A Controlled Evaluation of a Fitness and Nutrition Intervention Program on Cardiovascular Health in 10- to 12Year-Old Children,” Preventive Medicine, Vol. 24, No. 1, 1995, pp. 9-22. http://dx.doi.org/10.1006/pmed.1995.1003

[27] H. V. Lavelle, D. F. Mackay and J. P. Pell, "Systematic Review and Meta-Analysis of School-Based Interventions to Reduce Body Mass Index,” Journal of Public Health, Vol. 34, No. 3, 2012, pp. 360-369. http://dx.doi.org/10.1093/pubmed/fdr116

[28] M. de Onis, A. W. Onyango, E. Borghi, et al., "Development of a WHO Growth Reference for School-Aged Children and Adolescents," Bulletin of the World Health Organization, Vol. 85, No. 9, 2007, pp. 660-667.
http://dx.doi.org/10.2471/BLT.07.043497

[29] H. D. McCarthy, K. V. Jarrett and H. F. Crawley, “The Development of Waist Circumference Percentiles in British Children Aged 5.0-16.9 y,” European Journal of Clinical Nutrition, Vol. 55, No. 10, 2001, pp. 902-907. http://dx.doi.org/10.1038/sj.ejcn.1601240

[30] A. Gaya, A. Lemos, A. Gaya, et al., "Projeto Esporte Brasil (Proesp-Br). Manual de Testes e Avaliação,” 2012.

[31] M. Frenn, S. Malin and N. K. Bansal, "Stage-Based Interventions for Low-Fat Diet with Middle School Students,” Journal of Pediatric Nursing, Vol. 18, No. 1, 2003, pp. 36-45. http://dx.doi.org/10.1053/jpdn.2003.6

[32] J. Jiang, X. Xia, T. Greiner, et al., "The Effects of a 3-Year Obesity Intervention in Schoolchildren in Beijing," Child: Care, Health and Development, Vol. 33, No. 5, 2007, pp. 641-646. http://dx.doi.org/10.1111/j.1365-2214.2007.00738.x

[33] F. Salcedo Aguilar, V. Martinez-Vizcaino, M. Sanchez Lopez, et al., "Impact of an After-School Physical Activity Program on Obesity in Children," Journal of Pediatrics, Vol. 157, No. 1, 2010, pp. 36-42.e3.

[34] T. K. Harrell, B. M. Davy, J. L. Stewart, et al., "Effectiveness of a School-Based Intervention to Increase Health Knowledge of Cardiovascular Disease Risk Factors among Rural Mississippi Middle School Children,” Southern Medical Journal, Vol. 98, No. 12, 2005, pp. 1173-1180. http://dx.doi.org/10.1097/01.smj.0000182499.59715.07

[35] C. K. Haddock, W. R. Shadish, R. C. Klesges, et al., "Treatments for Childhood and Adolescent Obesity," Annals of Behavioral Medicine, Vol. 16, No. 3, 1994, pp. 235-244.

[36] G. Rose, “Sick Individuals and Sick Populations,” International Journal of Epidemiology, Vol. 14, No. 1, 1985, pp. 32-38. http://dx.doi.org/10.1093/ije/14.1.32 